\title{
Método para quantificação do consumo energético no ciclo de vida de equipamentos hidrossanitários
}

\author{
Method for quantifying the energy consumption in the \\ life cycle of plumbing fixtures
}

\section{Andreza Kalbusch Enedir Ghisi}

Andreza Kalbusch Laboratório de Ensino em Sistemas Prediais, Departamento de Engenharia

Universidade do Estado de Santa Catarina

Rua Paulo Malschitzki, s/n

J oinville - SC - Brasil CEP 89219-710

Tel.: (47) 4009-7936 E-mail: andreza@joinville.udesc.br

Enedir Ghisi

Laboratório de Eficiência Energética em Edificações, Departamento de Engenharia Civil Universidade Federal de Santa Catarina Florianópolis - SC - Brasil

Caixa Postal 476

CEP 88040-900

Tel.: (48) 3721-5185

E-mail: enedir@labeee.ufsc.br

Recebido em 10/09/11

Aceito em 25/08/12

\section{Resumo}

A

escolha entre diferentes materiais, produtos ou sistemas empregados na construção civil pode levar em consideração diferentes critérios, sejam estes econômicos, sociais, culturais e ambientais. No caso de equipamentos hidrossanitários, a avaliação econômica e do consumo de recursos, tais como a água, são os critérios mais comumente empregados. $\mathrm{O}$ presente artigo objetiva a proposição de um método para quantificação do consumo energético de equipamentos hidrossanitários com base no conceito de Análise do Ciclo de Vida. Essa quantificação permite a comparação entre o desempenho de diferentes equipamentos hidrossanitários com base no dispêndio energético total. No presente artigo o método proposto é aplicado em um estudo de caso analisando dois modelos de torneira (convencional e com fechamento hidromecânico). O consumo energético total no ciclo de vida das torneiras convencional e economizadora de água utilizadas no estudo foi de respectivamente, 151,66 MJ e 127,58 MJ. A etapa de uso das torneiras apresentou peso preponderante nos resultados, com participação de 64,6\% para a torneira convencional e 56,5\% para a torneira com fechamento hidromecânico. O método proposto se mostrou adequado para quantificação do consumo energético no ciclo de vida e posterior escolha entre diferentes equipamentos hidrossanitários que exerçam a mesma função.

Palabras clave: Análise do Ciclo de Vida. Consumo de energia. Equipamentos hidrossanitários.

\section{Abstract}

The choice among different materials, products and systems employed in the construction sector may take into consideration economic, social, cultural and environmental criteria. In the case of plumbing fixtures, economic evaluation and water consumption comparisons are the most frequently used criteria. This paper aims to propose a method for quantifying the energy consumption of plumbing fixtures based on the concept of Life Cycle Assessment. Such estimate allows a comparison between the performances of different plumbing fixtures in terms of energy consumption. The proposed method was applied in a case study to quantify energy consumption in the life cycle of two types of taps. The total energy consumption in the life cycle of conventional and water-saving taps used in the study was, respectively, 151.66 MJ and 127.58 MJ. The use phase accounts for $64.6 \%$ of energy consumption for conventional taps and $56.5 \%$ for self-closing taps. The proposed method has shown to be adequate for quantifying energy consumption in the life cycle and subsequent choice among different plumbing fixtures that perform the same function.

Keywords: Life Cycle Assessment. Energy consumption. Plumbing fixtures. 


\section{Introdução}

A preocupação com o ambiente e sua excessiva exploração pelo homem fizeram com que surgissem discussões a respeito e, com o tempo, que pesquisas cada vez mais aprofundadas começassem a ser realizadas. As discussões e pesquisas cresceram também no campo da construção civil. A norma NBR 15575-1 (ABNT, 2010) recomenda para o setor da construção civil a utilização de materiais que causem menor impacto ambiental, considerando-se desde a exploração dos recursos naturais até o destino final do material. A escolha de materiais deve dar-se com o conhecimento do respectivo impacto ambiental, que pode ser quantificado por meio da Avaliação do Ciclo de Vida de cada produto e ser disponibilizado pelos fabricantes.

Avaliação do Ciclo de Vida (ACV) é um método de gerenciamento ambiental utilizado para avaliar aspectos ambientais de produtos e tem sua estrutura pautada no conjunto de normas NBR ISO 14040 (ABNT, 2009a; ABNT, 2009b). Segundo o United Nations Environment Programme (UNITED..., 1996), ACV é o processo de avaliação dos efeitos que um produto tem sobre o ambiente durante todo seu período de vida. A ACV considera, dessa maneira, os efeitos ambientais nas etapas de extração, processamento, manufatura, distribuição, transporte, uso, reúso, manutenção, reciclagem e disposição final do produto.

Assim, ACV é um método que oferece suporte à tomada de decisões, podendo ser utilizada no desenvolvimento e melhoria de produtos, na comparação de diferentes produtos e em rotulagem ambiental (UNITED..., 1996). Segundo Ribeiro (2003), a ACV pode ser utilizada como ferramenta para melhoria de desempenho em determinadas etapas do ciclo de vida de um produto ou sistema, já que fornece informações sobre os impactos ambientais potenciais em cada etapa. Segundo o autor, o método também pode ser utilizado para comparação entre produtos ou sistemas com funções equivalentes.

Segundo Soares, Souza e Pereira (2006), a aplicação de ACV, frequentemente utilizada nas áreas empresarial e industrial, é reconhecida como de grande valia para aplicação no setor da construção civil. A construção civil é uma atividade que produz grandes impactos ambientais, desde a fase de extração e fabricação de matériasprimas até a renovação ou demolição. Os autores ressaltam também as limitações da aplicação de ACV na avaliação de impactos ambientais associados à construção civil. Essas dificuldades iniciam-se na fase de coleta de informações, já que não é simples a obtenção de bases de dados confiáveis para os materiais empregados na construção civil.

Silva (2003) também aponta inúmeras dificuldades para a aplicação dos conceitos relacionados à ACV no setor da construção civil, porém evidencia o cunho científico relacionado ao emprego de tais conceitos. Apesar das limitações, Soares, Souza e Pereira (2006) afirmam que a utilização de conceitos de ACV na avaliação de produtos da construção civil possibilita a especificação de materiais de modo a promover melhoria ambiental (e também econômica) nas diversas etapas do ciclo de vida do produto da construção civil estudado.

Estudos como o desenvolvido por Abeysundara, Babel e Gheewala (2009) ressaltam a importância do consumo energético como forma de comparação de materiais e produtos em termos ambientais. Verbeeck e Hens (2010) discorrem sobre a importância do tema energia em ACV de edifícios, e Bribián, Usón e Scarpellini (2009), sobre o consumo de energia em um estudo de ACV para certificação de edifícios. De acordo com Silveira, Reis e Galvão (2000), a questão energética é primordial para o planejamento baseado nas premissas da sustentabilidade. Os referidos autores afirmam que os recursos energéticos fazem parte da agenda estratégica de todo e qualquer país. Os autores ressaltam também as dimensões ambiental, econômica e social ligadas ao consumo de energia no mundo.

Huberman e Pearlmutter (2007) realizaram um estudo sobre o ciclo de vida energético de materiais de construção em Israel e apontaram a importância do conhecimento da energia embutida e da energia operacional de um edifício localizado no deserto. Blanchard e Reppe (1998) realizaram um estudo de ACV de uma residência nos Estados Unidos, focando os resultados na quantificação de energia consumida e no potencial de aquecimento global durante o ciclo de vida da edificação. Arena e Rosa (2003) compararam cenários com uso de diferentes materiais e consequentes consumos energéticos em edifícios escolares na Argentina. Tavares e Lamberts (2004) realizaram estudos comparativos sobre o consumo energético de edificações na Suécia, Austrália e Brasil. Os estudos citados foram elaborados para diferentes regiões do globo com diferentes condições climáticas e de geração energética.

No Brasil, Taborianski, Simoni e Prado (2008) elaboraram um inventário de consumo de energia no ciclo de vida de materiais utilizados em fachadas de edifícios. Soares e Pereira (2004) 
realizaram uma pesquisa que envolve o inventário do ciclo de vida de pisos e tijolos cerâmicos, e Tavares (2006) elaborou uma metodologia de Análise do Ciclo de Vida Energético para edificações residenciais brasileiras. Os autores citados trabalharam com ACV de produtos ou sistemas relacionados à construção civil no país. Neste artigo o método ACV é utilizado para comparação entre os consumos energéticos totais de torneiras levando-se em consideração a realidade nacional.

O objetivo do presente artigo é a proposição de um método para quantificação do consumo energético total no ciclo de vida de equipamentos hidrossanitários. O mesmo é empregado no cálculo do consumo de energia de dois modelos de torneiras instaladas nos lavatórios de um bloco de salas de aula do campus do Centro de Ciências Tecnológicas (CCT) da Universidade do Estado de Santa Catarina (UDESC), no município de Joinville, SC.

\section{Método}

A NBR 5626 (ABNT, 1998) define aparelho sanitário como componente destinado ao uso da água ou recebimento de dejetos, pertencendo ao Sistema Predial de Esgoto Sanitário, na maioria dos casos. Bacias sanitárias, lavatórios, pias de cozinha, banheiras, lavadoras de roupas e lavadoras de louças são exemplos de aparelhos sanitários. A referida norma define peça de utilização como componente instalado a jusante do sub-ramal no Sistema Predial de Água Fria, que permite a utilização da água e, em alguns casos, também o ajuste de vazão. Define também componente como qualquer produto integrante do Sistema Predial de Água Fria que cumpra uma função individualmente.

A especificação de equipamentos que promovam o uso racional da água, objeto do presente estudo, envolve o conhecimento de componentes, tanto do Sistema Predial de Água Fria quanto do Sistema Predial de Esgoto Sanitário. No presente artigo a nomenclatura utilizada para tais componentes é “equipamentos hidrossanitários”.

O método consiste na aplicação do conceito de Análise do Ciclo de Vida para a determinação do consumo energético de equipamentos hidrossanitários. Como a função de tais equipamentos é disponibilizar água para consumo dos usuários dos sistemas prediais de distribuição de água, a eficiência com relação à economia de água desse equipamento tem influência direta no consumo energético. Isso ocorre porque, se o equipamento hidrossanitário levar a um consumo menor de água, em consequência haverá um consumo menor de energia necessária ao tratamento de água, bombeamento, aquecimento e posterior tratamento dos efluentes gerados.

Para considerar fatores como os mencionados, a análise quantifica o consumo de energia desde a extração da matéria-prima até o descarte final de equipamentos hidrossanitários. Assim, é possível a comparação entre equipamentos hidrossanitários com base no consumo energético no ciclo de vida.

\section{Fases do ciclo de vida dos equipamentos}

As fases do ciclo de vida de equipamentos hidrossanitários consideradas no presente método dividiram-se nas fases principais de produção, uso e disposição final. A fase de produção envolve a extração de materiais e seu beneficiamento, de modo a possibilitar a fabricação do equipamento hidrossanitário. A fase de uso engloba o consumo energético gerado pela utilização e eventual manutenção dele, e a fase de disposição final, o consumo energético relativo ao descarte, considerando-se a possibilidade de reciclagem. As subdivisões consideradas para as fases de produção, uso e disposição final são:

(a) fase de produção:

- extração da matéria-prima;

- processamento e transporte da matéria-prima;

- aquisição de materiais reciclados;

- processamento e transporte de materiais reciclados;

- manufatura do equipamento (indústria de equipamentos hidrossanitários); e

- transporte do equipamento.

(b) fase de uso:

- utilização do equipamento; e

- manutenção do equipamento.

(c) fase de disposição final:

- transporte;

- reciclagem; e

- descarte.

A Figura 1 ilustra as fases do ciclo de vida de equipamentos hidrossanitários propostas no presente método, representando-se por meio de setas as necessidades relativas ao transporte de materiais. 


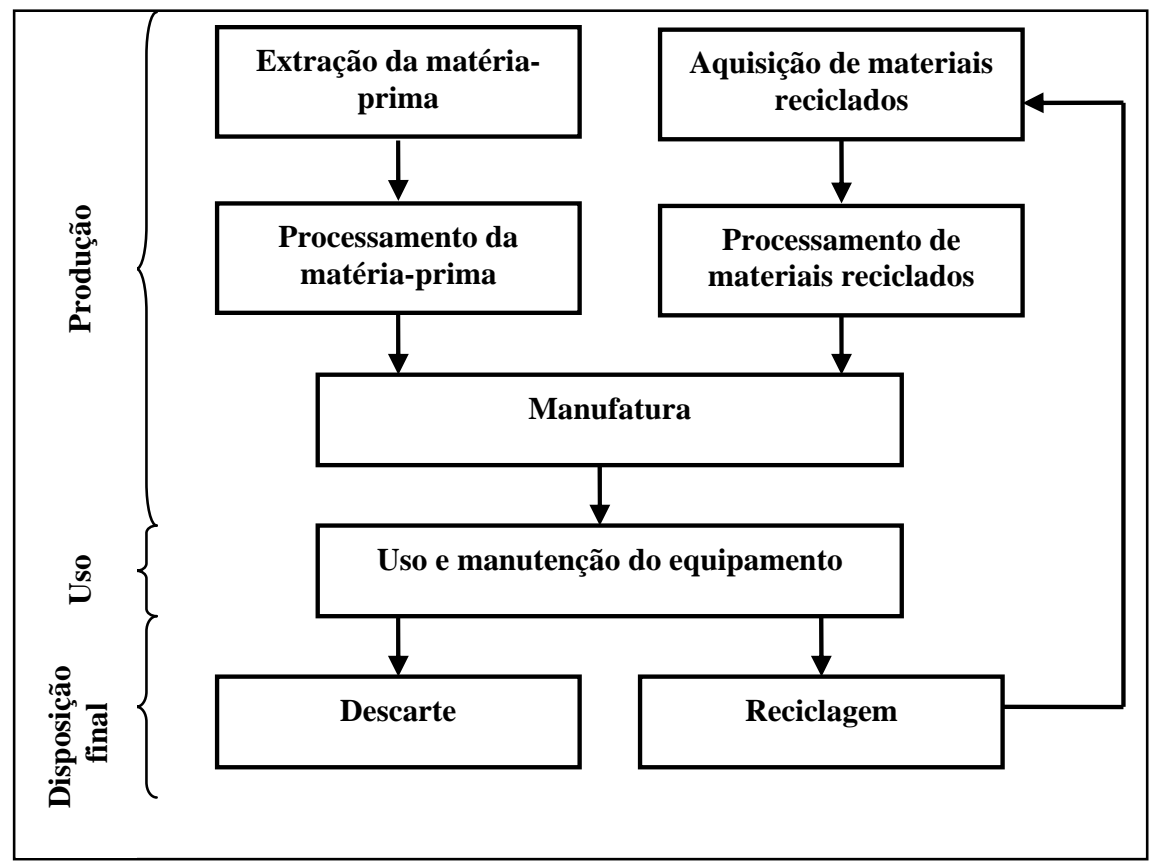

Figura 1 - Fases do ciclo de vida de equipamentos hidrossanitários

É importante ressaltar que os valores referentes a eventuais desperdícios em cada uma das fases apresentadas também devem estar embutidos nos cálculos, sendo, portanto, considerados no presente estudo.

\section{Coleta de dados e cálculo dos impactos}

Os dados coletados devem ser calculados ou obtidos por meio de pesquisas de campo junto a fabricantes de equipamentos hidrossanitários, na literatura ou em bancos de dados confiáveis. No que concerne à qualidade dos dados, eles devem preferencialmente apresentar idade inferior a dez anos e refletir a realidade nacional. Quando não for possível atender a esses requisitos, deve haver documentação a respeito. Além disso, todos os dados apresentados devem ser referenciados.

\section{Cálculo dos indicadores referentes ao consumo de energia total}

O consumo de energia total leva em consideração a quantidade de energia (em MJ) das diversas fases do ciclo de vida dos equipamentos e as respectivas necessidades de transporte:

(a) energia embutida na extração da matériaprima;

(b) energia embutida no processamento da matéria-prima;

(c) energia embutida na aquisição de materiais reciclados; (d) energia embutida no processamento de materiais reciclados;

(e) energia embutida na manufatura do equipamento (na indústria de equipamentos hidrossanitários);

(f) consumo de energia para utilização do equipamento (energia operacional);

(g) energia necessária para manutenção do equipamento;

(h) energia necessária para reciclagem; e

(i) energia necessária no processo de descarte.

Assim, o consumo de energia total leva em consideração as contribuições das diversas fases do ciclo de vida dos equipamentos, conforme a Equação 1.

$$
\mathrm{CE}=\mathrm{EE}_{\mathrm{p}}+\mathrm{CE}_{\mathrm{u}}+\mathrm{CE}_{\mathrm{di}}
$$

Onde:

CE é o consumo de energia total (MJ);

$E_{\mathrm{p}}$ é a energia embutida na fase de produção do equipamento (MJ);

$\mathrm{CE}_{\mathrm{u}}$ é o consumo de energia para utilização e manutenção do equipamento (MJ); e

$\mathrm{CE}_{\mathrm{di}}$ é a energia necessária no processo de descarte ou reciclagem $(\mathrm{MJ})$. 


\section{Consumo de energia na fase de produção}

O consumo de energia na fase de produção leva em consideração a energia embutida na extração e processamento da matéria-prima, na aquisição e processamento de materiais reciclados e no processo industrial de fabricação do equipamento hidrossanitário, conforme a Equação 2.

$\mathrm{EE}_{\mathrm{p}}=\mathrm{EE}_{\mathrm{mp}}+\mathrm{EE}_{\mathrm{rc}}+\mathrm{EE}_{\mathrm{pr}}$

Eq. 2

Onde:

$E_{\mathrm{p}}$ é a energia embutida na fase de produção do equipamento (MJ);

$E E_{m p}$ é a energia embutida na extração e processamento da matéria-prima (MJ);

$E E_{\mathrm{rc}}$ é a energia embutida na aquisição e processamento de materiais reciclados (MJ); e

$\mathrm{EE}_{\mathrm{pr}}$ é a energia embutida na manufatura do equipamento (indústria) (MJ).

Devem ser consideradas, ao analisar a extração e o transporte das matérias-primas utilizadas na produção dos equipamentos, as massas dos componentes do equipamento hidrossanitário, além das respectivas distâncias de transporte.

Quanto às necessidades de transporte de matériaprima, devem ser consideradas as distâncias percorridas para que o material chegue ao fabricante dos equipamentos hidrossanitários, o tipo de transporte e os respectivos consumos de energia associados (Equação 3).

$\mathrm{EE}_{\mathrm{mp}}=\sum_{i=1}^{n}\left(\mathrm{M}_{\mathrm{mpi}} \times \mathrm{CE}_{\mathrm{exti}}+\mathrm{D}_{\mathrm{mpi}} \mathrm{x}\right.$ Pc x CEt $\left.\mathrm{mpi}\right)$

Onde:

$E_{m p}$ é a energia embutida na extração e processamento da matéria-prima (MJ);

n é o número de materiais analisados;

$\mathrm{M}_{\mathrm{mp}}$ é a massa do material (kg);

$\mathrm{CE}_{\text {ext }}$ é o consumo de energia associado à extração e processamento do material ( $\mathrm{MJ} / \mathrm{kg})$;

$\mathrm{D}_{\mathrm{mp}}$ é a distância de transporte da matéria-prima (km);

Pc é a percentagem representativa da massa do material em comparação à carga total transportada no meio de transporte (\%); e

$\mathrm{CE}_{\text {tmp }}$ é o consumo de energia associado ao transporte da matéria-prima (MJ/km).

Se houver utilização de materiais provenientes de reciclagem, a energia embutida na aquisição e processamento de tais materiais também deverá ser considerada, de acordo com a Equação 4.
$\mathrm{EErc}=\sum_{i=1}^{n} \quad\left(\mathrm{M}_{\mathrm{rci}} \times \mathrm{CE}_{\mathrm{rci}}+\mathrm{D}_{\mathrm{rci}} \times \mathrm{Pc} \times \mathrm{CE}_{\mathrm{trci}}\right)$

Eq. 4

Onde:

$E_{\mathrm{rc}}$ é a energia embutida na aquisição e processamento de materiais reciclados (MJ);

n é o número de materiais analisados;

$\mathrm{M}_{\mathrm{rc}}$ é a massa do material reciclado (kg);

$\mathrm{CE}_{\mathrm{rc}}$ é o consumo de energia associado à reciclagem e processamento do material $(\mathrm{MJ} / \mathrm{kg})$;

$\mathrm{D}_{\mathrm{rc}}$ é a distância de transporte do material reciclado $(\mathrm{km})$;

Pc é a percentagem representativa da massa do material em comparação à carga total transportada no meio de transporte (\%); e

$\mathrm{CE}_{\text {trc }}$ é o consumo de energia associado ao transporte do material reciclado $(\mathrm{MJ} / \mathrm{km})$.

A energia necessária para a produção e o transporte do equipamento hidrossanitário (do local de produção ao local de utilização) também deve ser considerada, conforme a Equação 5.

$\mathrm{EE}_{\mathrm{pr}}=\mathrm{M}_{\mathrm{eq}} \times \mathrm{CE}_{\mathrm{pr}}+\mathrm{D}_{\mathrm{pr}} \times$ Pc x CE $\mathrm{E}_{\mathrm{tpr}}$

Eq. 5

Onde:

$\mathrm{EE}_{\mathrm{pr}}$ é a energia embutida na manufatura do equipamento (indústria) (MJ);

$\mathrm{M}_{\text {eq }}$ é a massa do equipamento analisado (kg);

$\mathrm{CE}_{\mathrm{pr}}$ é o consumo de energia associado à manufatura do equipamento (MJ/kg);

$\mathrm{D}_{\mathrm{pr}}$ é a distância de transporte para distribuição do equipamento $(\mathrm{km})$;

Pc é a percentagem representativa da massa do equipamento em comparação à carga total transportada no meio de transporte (\%); e

$\mathrm{CE}_{\text {tpr }}$ é o consumo de energia associado ao transporte do equipamento $(\mathrm{MJ} / \mathrm{km})$.

\section{Consumo de energia na fase de uso}

É importante determinar, na fase de uso, o consumo de energia de equipamentos como chuveiros com sistemas de aquecimento elétrico e a gás, torneiras e mictórios acionados com sensor de presença e outros equipamentos que utilizem fontes energéticas. Também devem ser consideradas as necessidades energéticas para bombeamento da água nos sistemas prediais, que são tanto maiores quanto maior for o consumo de água. Tais estimativas devem ser realizadas levando-se em consideração os projetos atualizados dos sistemas hidrossanitários, o número de usuários dos sistemas e outras 
particularidades na utilização dos sistemas prediais da edificação em estudo.

Outros dados a serem considerados referem-se ao consumo da energia despendida no tratamento e abastecimento de água e na coleta e tratamento dos efluentes gerados. Existem alguns estudos que estimam o consumo energético para o fornecimento de água tratada e tratamento de efluentes, como os apresentados por Tsutiya (1997) e Hirata (2009), ambos em São Paulo.

No presente estudo, a consulta desses dados é realizada por meio do relatório publicado pelo Sistema Nacional de Informações sobre Saneamento (SNIS), que apresenta um diagnóstico dos serviços de água e esgoto no país (BRASIL, 2007). No documento são calculados o índice de consumo de energia elétrica em sistemas de abastecimento de água e o índice de consumo de energia elétrica em sistemas de esgotamento sanitário nos municípios brasileiros, ambos expressos em $\mathrm{kWh} / \mathrm{m}^{3}$. Dessa forma, pode-se proceder aos cálculos referentes ao consumo energético para o tratamento e abastecimento de água e para coleta e tratamento dos efluentes gerados levando-se em consideração os valores do município em que é realizado o estudo.

A Equação 6 demonstra o método proposto de cálculo para o consumo de energia na utilização e manutenção do equipamento.

$\mathrm{CE}_{\mathrm{u}}=\mathrm{CE}_{\mathrm{ut}} \mathrm{x} \mathrm{VU}+\mathrm{CE}_{\mathrm{aq}}+\left(\mathrm{CE}_{\mathrm{bo}}+\mathrm{CE}_{\mathrm{ab}}+\right.$

$\left.\mathrm{CE}_{\mathrm{esg}}\right) \times\left(\mathrm{CA}_{\mathrm{eq}} \times \mathrm{VU}\right)+\mathrm{CE}_{\mathrm{m}}$

Onde:

$\mathrm{CE}_{\mathrm{u}}$ é o consumo de energia para utilização e manutenção do equipamento (MJ);

$\mathrm{CE}_{\mathrm{ut}}$ é o consumo de energia direto (operacional) do equipamento, por ano (MJ/ano);

VU é a vida útil (anos);

$\mathrm{CE}_{\mathrm{aq}}$ consumo de energia para aquecimento de água (MJ);

$\mathrm{CE}_{\mathrm{bo}}$ é o consumo de energia para bombeamento de água $\left(\mathrm{MJ} / \mathrm{m}^{3}\right)$;

$\mathrm{CE}_{\mathrm{ab}}$ é o consumo de energia para abastecimento público de água $\left(\mathrm{MJ} / \mathrm{m}^{3}\right)$;

$\mathrm{CE}_{\text {esg }}$ é o consumo de energia para coleta e tratamento de esgoto sanitário $\left(\mathrm{MJ} / \mathrm{m}^{3}\right)$;

$\mathrm{CA}_{\mathrm{eq}}$ é o consumo anual de água do equipamento ( $\left.\mathrm{m}^{3} / \mathrm{ano}\right)$; e

$\mathrm{CE}_{\mathrm{m}}$ é o consumo de energia associado a necessidades de manutenção (MJ).

\section{Consumo de energia na fase de disposição final}

Na fase de disposição final dos equipamentos, assim como no caso do consumo de água, para o consumo de energia, em caso de simples descarte em aterro, o que se considera são as necessidades relativas a transporte. Quanto à reciclagem de materiais, deve ser verificada a quantidade de material enviado para reciclagem em ciclo aberto (excluindo o que é reciclado diretamente na produção do equipamento hidrossanitário em estudo) e as respectivas distâncias de transporte, conforme a Equação 7.

$\mathrm{CE}_{\mathrm{di}}=\mathrm{D}_{\mathrm{di}} \times$ Pc x $\mathrm{CE}_{\mathrm{tdi}}+\mathrm{D}_{\text {re }} \times$ Pc x CE

Eq. 7

Onde:

$\mathrm{CE}_{\mathrm{di}}$ é a energia necessária no processo de descarte ou reciclagem $(\mathrm{MJ})$;

$\mathrm{D}_{\text {di }}$ é a distância de transporte para descarte do equipamento $(\mathrm{km})$;

Pc é a percentagem representativa da massa do equipamento em comparação à carga total transportada no meio de transporte (\%);

$\mathrm{CE}_{\text {tdi }}$ é o consumo de energia associado ao transporte para descarte do equipamento (MJ/km);

$\mathrm{D}_{\text {re }}$ é a distância de transporte para disposição final do material para reciclagem $(\mathrm{km})$; e

$\mathrm{CE}_{\text {tre }}$ é o consumo de energia associado ao transporte do material para reciclagem $(\mathrm{MJ} / \mathrm{km})$.

\section{Comparação entre diferentes equipamentos hidrossanitários}

As comparações para escolha entre os diferentes equipamentos deve sempre levar em conta a unidade funcional, ou seja, as comparações devem ser realizadas entre equipamentos que desempenhem a mesma função, em um dado período de tempo.

É importante verificar questões que gerem subjetividade na análise. Por exemplo, deve-se observar se a substituição de um equipamento convencional por um equipamento economizador, que gere maior conforto ao usuário ao ser utilizado, não levaria a um tempo maior de uso e, como consequência, a um consumo maior de insumos. Para contornar problemas como o mencionado, é importante que cada sistema seja analisado como um sistema único, com suas particularidades, que devem ser levadas em consideração. Nesse caso, a sugestão é que sejam adotados procedimentos para experimentação e medições in loco.

O método proposto visa determinar o consumo energético no ciclo de vida de equipamentos 
hidrossanitários, sendo utilizado como uma abordagem atribucional (uma vez que atribui os impactos do ciclo de vida relativos a determinado equipamento). $\mathrm{Na}$ abordagem atribucional é determinado, em dado período, o impacto gerado por um produto ou sistema levando-se em consideração o ciclo de vida no período estudado (que pode ser presente, passado ou futuro) (UNITED..., 2002).

\section{Aplicação do método proposto em um estudo de caso}

Com a finalidade de aplicar o método proposto, o presente estudo de caso propõe a avaliação do consumo energético durante o ciclo de vida de dois diferentes modelos de torneiras (uma torneira convencional e outra torneira com fechamento hidromecânico) instaladas em um dos blocos de salas de aula do campus do CCT da UDESC. O bloco possui 18 salas de aula, dois banheiros femininos e dois banheiros masculinos, divididos em dois andares.

Conforme anteriormente descrito, para a coleta de dados, primeiramente se deve realizar um levantamento dos edifícios e dos equipamentos hidrossanitários existentes. No estudo de caso, a aquisição desses dados dá-se por meio do levantamento dos projetos dos edifícios existentes no campus e de levantamentos in loco.

Para os dados referentes ao ciclo de vida dos equipamentos hidrossanitários, na fase de produção, a coleta dos dados utilizados nos cálculos do consumo energético dá-se por meio de consultas aos principais fornecedores de matériasprimas e fabricantes dos equipamentos, além de pesquisas acadêmicas. São consideradas as distâncias dos locais de produção dos materiais até o local de produção dos equipamentos. Na etapa de fabricação são utilizados dados da indústria de equipamentos hidrossanitários e para o transporte dos equipamentos produzidos, é considerada a distância do local de fabricação até o local de aplicação, o campus universitário em estudo.

Na fase de uso, os dados referentes ao consumo de água do equipamento hidrossanitário devem, preferencialmente, ser obtidos por meio de medições in loco. Para o cálculo do consumo de energia na utilização do equipamento, deve ser considerado o consumo de energia (se houver) fornecido pelo fabricante do equipamento hidrossanitário analisado, o consumo de energia para bombeamento de água, obtido com o fabricante da motobomba e por meio de dados de consumo de água da edificação. Também deve ser considerado o consumo de energia para abastecimento público de água e para coleta e tratamento de esgoto sanitário. Tais dados devem ser obtidos por meio do Sistema Nacional de Informações sobre Saneamento ou por meio de outras pesquisas que reflitam a realidade local.

É importante ressaltar que, apesar de não ser definido como consumo direto de energia do equipamento, o consumo de energia para possibilitar a utilização da água no ponto de consumo possui grande relevância na comparação entre os dois modelos de torneira analisados. Os dados referentes ao consumo de energia associado a necessidades de manutenção podem ser obtidos com pesquisas in loco ou em fontes confiáveis.

Para quantificar o consumo de água na fase de uso, o bloco de salas de aula teve o consumo de água de todos os equipamentos hidrossanitários analisado no período de 06/04/2011 a 23/05/2011. Após isso, as 14 torneiras convencionais foram substituídas por 14 torneiras com fechamento hidromecânico, e o consumo de água foi medido do período de 24/05/2011 a 03/07/2011. A Figura 2 mostra o hidrômetro instalado em um dos pontos de consumo, antes e depois da troca de torneiras.

Na fase de disposição final é considerada apenas a deposição em locais apropriados para receber os resíduos, sem considerar cenários com reciclagem de materiais. A possibilidade de reciclagem dos diferentes materiais que compõem os equipamentos hidrossanitários analisados é uma das sugestões para o desenvolvimento de outros trabalhos utilizando o método proposto.

Os dados referentes a distâncias de transporte para descarte do equipamento e/ou de suas partes devem ser obtidos com os órgãos ambientais locais. Os dados de consumo de energia associado ao transporte do equipamento podem ser obtidos na literatura e em pesquisas que relacionem o tipo de transporte utilizado na região e o consumo de recursos energéticos.

\section{Resultados}

A fim de testar a aplicação do método proposto, o mesmo é empregado no estudo de implantação do Programa de Uso Racional da Água no campus do CCT da UDESC, no município de Joinville, SC. O campus é constituído de 14 edifícios, distribuídos em uma área de aproximadamente $62.000 \mathrm{~m}^{2}$. Todo suprimento de água do campus é realizado pela rede de serviço de abastecimento da companhia de saneamento municipal, não existindo nenhuma fonte alternativa de abastecimento. 


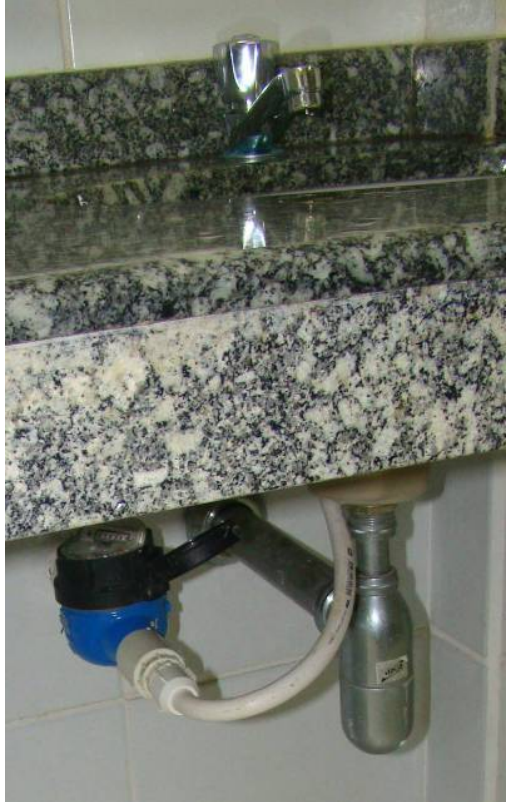

(a)

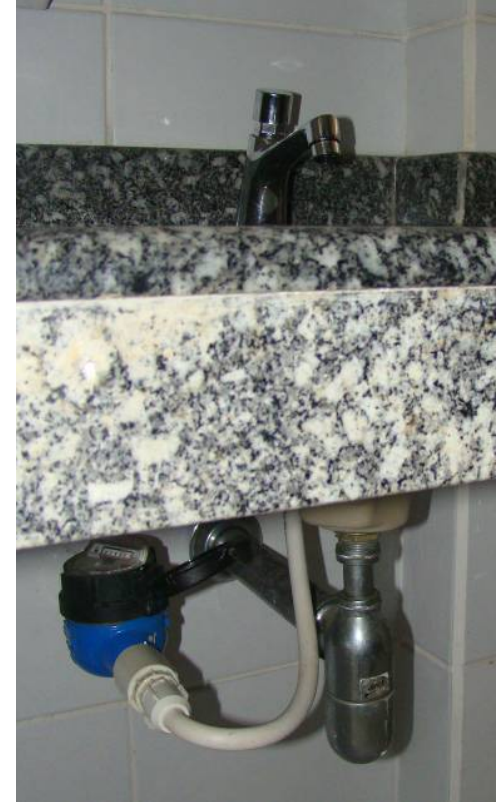

(b)

Figura 2 - Hidrômetro instalado em uma torneira (a) convencional e (b) economizadora de água

Tabela 1 - Valores médio, mínimo e máximo para o índice de consumo de água nas torneiras

\begin{tabular}{|c|c|c|c|c|c|c|c|c|}
\hline \multicolumn{3}{|c|}{ Consumo de água $\left(\mathrm{m}^{3}\right)$} & \multicolumn{3}{|c|}{ Número de usuários } & \multicolumn{3}{|c|}{ Índice de consumo (l/usuário/dia) } \\
\hline Média & Mínimo & Máximo & Média & Mínimo & Máximo & Média & Mínimo & Máximo \\
\hline \multicolumn{9}{|c|}{ Torneira convencional (medições entre 06/04/11 e 23/05/11) } \\
\hline 0,462 & 0,192 & 0,724 & 876 & 426 & 1342 & 0,538 & 0,312 & 0,946 \\
\hline \multicolumn{9}{|c|}{ Torneira economizadora de água (medições entre 24/05/11 e 03/07/11) } \\
\hline 0,383 & 0,143 & 0,931 & 980 & 426 & 2234 & 0,396 & 0,242 & 0,789 \\
\hline
\end{tabular}

Para o estudo de caso, o perfil de consumo de água da edificação em que estão previstas as intervenções de substituição de equipamentos é traçado, incluindo medições em duas etapas:

(a) pontos de consumo com torneiras convencionais instaladas; e

(b) pontos de consumo com torneiras economizadoras de água instaladas.

Com medições in loco, os dados de consumo de água decorrentes da operação do equipamento convencional e do equipamento economizador refletem a realidade da edificação analisada (Tabela 1).

O índice de consumo (IC), em litros por usuário por dia, é calculado, uma vez que há variação no número de usuários durante a semana. Para o cálculo do consumo anual e posterior comparação entre os dois cenários de análise são considerados 223 dias letivos por ano e um número fixo de 921 usuários por dia.

No presente estudo, tendo em vista a tipologia do edifício e aspectos como manutenabilidade e durabilidade média dos equipamentos no campus, a vida útil considerada (ou seja, a fase de uso) para os equipamentos hidrossanitários é de 4 anos. Os resultados referentes aos índices relativos às diferentes fases do ciclo de vida para os equipamentos existentes e para os equipamentos economizadores são apresentados a seguir.

\section{Quantificação do consumo energético}

\section{Consumo de energia na fase de produção}

Para o cálculo do consumo de energia na fase de produção das torneiras convencional e economizadora de água foram coletados dados de composição de duas torneiras junto a um dos maiores fabricantes de metais sanitários no Brasil. As informações referentes à composição de dois modelos de torneira podem ser verificadas na Tabela 2.

A Tabela 3 apresenta o consumo energético na extração de matéria-prima e beneficiamento de materiais considerado no estudo de caso. Os dados são prioritariamente de fontes nacionais. Apenas 
quando não havia dados brasileiros disponíveis foram utilizados dados de referências estrangeiras. No caso do aço inoxidável foram utilizados dados nacionais disponíveis para a matéria-prima aço. Para o beneficiamento do latão foram utilizados dados de uma indústria (fonte confidencial) que utiliza 7,0 kWh/kg de latão beneficiado. Esse valor foi acrescido ao consumo energético para extração e beneficiamento dos materiais cobre e zinco na Tabela 3.

O consumo de energia para a produção do polioximetileno (POM) não foi encontrado em relatórios setoriais ou estudos acadêmicos. Foram, então, utilizados os valores de consumo energético de uma indústria brasileira (confidencial), do período de janeiro de 2010 a junho de 2011. Para a produção de cada quilograma de polioximetileno, a indústria que disponibilizou os dados emprega 0,4 kWh de energia elétrica.

Para a quantificação da energia envolvida no transporte de materiais, Cybis e Santos (2000) utilizaram, para transporte rodoviário em caminhões pesados, o valor de um litro de óleo diesel para cada 3,0 km, mesmo consumo médio considerado por Tavares (2006). O referido autor realizou ainda a transformação considerando-se o poder calorífico do combustível de $35 \mathrm{GJ} / \mathrm{m}^{3}$.

De acordo com o estudo realizado por Veiga (2011) em uma indústria fabricante de metais sanitários, o consumo de energia elétrica para a fabricação das torneiras é de $5,41 \mathrm{kWh} / \mathrm{kg}$ por equipamento produzido. Para os modelos de torneira em questão a fonte energética é apenas elétrica, embora a indústria analisada seja atendida também por energia proveniente de rede de gás natural.

\section{Consumo de energia na fase de uso}

No período de quatro anos, para a manutenção dos equipamentos é considerada a limpeza dos arejadores a cada seis meses, realizada pelos funcionários do campus. Foi considerado que tal limpeza não acarreta consumo significativo de água ou energia para o presente estudo de caso.

Outro dado importante refere-se à energia para bombeamento da água nos sistemas prediais. Pertel et al. (2008) calcularam a relação entre a energia necessária para bombas de recalque e o volume de água levado ao reservatório superior como 1,65 $\mathrm{kWh} / \mathrm{m}^{3}$ em um edifício de 20 andares.

Tabela 2 - Materiais componentes das torneiras modelo Itapema Bella e Pressmatic 110

\begin{tabular}{c|c|c|c}
\hline & $\begin{array}{l}\text { Torneira } \\
\text { convencional } \\
\text { Modelo: } \\
\text { Itapema Bella }\end{array}$ & $\begin{array}{l}\text { Torneira } \\
\text { economizadora } \\
\text { Modelo: } \\
\text { Pressmatic } 110\end{array}$ \\
\hline Material & Massa (g) & Material & Massa (g) \\
\hline Latão & 614,5 & Latão & 591,4 \\
\hline Cerâmica & 3,4 & Aço inoxidável & 14,1 \\
\hline Plástico (POM) & 81,5 & Plástico (POM) & 60,7 \\
\hline Borracha & 1,5 & Borracha & 3,1 \\
\hline Papel/Papelão & 8,2 & Papel/Papelão & 88,5 \\
\hline Total & $\mathbf{7 0 9 , 1}$ & Total & $\mathbf{7 5 7 , 8}$ \\
\hline
\end{tabular}

Nota: o percentual considerado de cobre no latão é de aproximadamente $61 \%$ e de zinco, $39 \%$

Fonte: Veiga (2011).

Tabela 3 - Consumo energético considerado na extração e beneficiamento das matérias-primas

\begin{tabular}{l|c}
\multicolumn{1}{c|}{ Material } & Consumo energético total (MJ/kg) \\
\hline Cobre (incluindo transformação em latão) & 38,60 \\
\hline Zinco (incluindo transformação em latão) & 73,20 \\
\hline Aço & 23,03 \\
\hline Cerâmica & 3,73 \\
\hline Borracha & 143,00 \\
\hline Papel/Papelão & 17,51
\end{tabular}

Fonte: Ministério de Minas e Energia (2009; 2010), Associação Brasileira de Celulose e Papel (2010), Scheuer, Keoleian e Reppe (2003), Seppälä et al. (2002) e Norgate, Jahanshahi e Rankin (2007). 
De acordo com Spezzia Junior (2009), o cálculo simplificado do consumo diário de energia para o bombeamento de água em sistemas prediais pode ser estimado pela Equação 8.

$\mathrm{CE}_{\mathrm{mb}}=(\mathrm{PM} \times \mathrm{FC} \times \mathrm{FS}) \times$ Tfunc

Eq. 8

Onde:

$\mathrm{CE}_{\mathrm{mb}}$ é o consumo de energia da motobomba (KWh);

PM é a potência mecânica do motor elétrico, em $\mathrm{CV}$;

FC é o fator de conversão, igual a 0,735;

FS é o fator de serviço do motor (em geral igual a 1,15); e

Tfunc é o tempo de funcionamento do motor, em horas.

O consumo de energia para bombeamento da água deve ser calculado de acordo com a Equação 9.

$\mathrm{CE}_{\mathrm{bo}}=\left(\mathrm{CE}_{\mathrm{mb}} \times 3,6\right) / \mathrm{CA}_{\mathrm{ed}}$

Eq. 9

Onde:

$\mathrm{CE}_{\mathrm{bo}}$ é o consumo de energia para bombeamento de água $\left(\mathrm{MJ} / \mathrm{m}^{3}\right)$;

$\mathrm{CE}_{\mathrm{mb}}$ é consumo de energia da motobomba (KWh); e

$\mathrm{CA}_{\mathrm{ed}}$ é consumo de água do edifício $\left(\mathrm{m}^{3}\right)$.

No estudo de caso foi considerado que a potência mecânica do motor elétrico da motobomba instalada no bloco de salas de aula em análise é igual a $0,25 \mathrm{CV}$, e o tempo de funcionamento no estudo de caso é igual a $2 \mathrm{~h}$ por dia para o consumo total do edifício, igual a $2,78 \mathrm{~m}^{3} /$ dia. Nesse caso, o consumo energético para bombeamento da água no edifício foi calculado como $0,547 \mathrm{MJ} / \mathrm{m}^{3}$.

Outro ponto a ser considerado é o consumo energético para provisão de água potável e posterior coleta e tratamento de esgoto sanitário. De acordo com o Sistema Nacional de Informações sobre Saneamento (BRASIL, 2007), os dados para o consumo energético no tratamento e abastecimento de água e coleta e tratamento de esgotos sanitários para a cidade de Joinville são:

(a) índice de consumo de energia elétrica em sistemas de abastecimento de água: $1,908 \mathrm{MJ} / \mathrm{m}^{3}$; e

(b) índice de consumo de energia elétrica em sistemas de esgotamento sanitário: 0,648 $\mathrm{MJ} / \mathrm{m}^{3}$.

\section{Consumo de energia na fase de disposição final}

No que se refere às necessidades de transporte para descarte dos equipamentos, no cálculo do consumo energético, o desempenho considerado para os caminhões é de 3,0 km por litro de óleo diesel (TAVARES, 2006). No cálculo do consumo energético para transporte é considerado que todas as 14 torneiras do edifício alcançaram o fim da vida útil. Assim, o consumo energético desse transporte é dividido pelo número total de torneiras transportadas.

\section{Consumo de energia no ciclo de vida: torneira convencional}

A Tabela 4 apresenta o consumo de energia para extração, beneficiamento e transporte das matériasprimas até a indústria que fabrica a torneira convencional. $\mathrm{O}$ consumo energético na extração e beneficiamento dos metais cobre e zinco já inclui o processo de transformação em latão. Para o cálculo das massas de cobre e latão foi considerado o percentual de $61 \%$ de cobre e de $39 \%$ de zinco na composição em massa do latão. O percentual da carga no transporte calculado para cada tipo de matéria-prima leva em consideração a relação entre a massa de material necessário para a produção da torneira e a massa total do mesmo material transportado em caminhão pesado. A energia embutida nos processos de extração, beneficiamento e transporte das matérias-primas que compõem a torneira convencional foi calculada de acordo com a Equação 3 como 34,24 MJ.

A Tabela 5 apresenta o consumo de energia para manufatura da torneira na indústria de metais sanitários analisada e posterior transporte ao campus universitário. O percentual da carga no transporte calculado para a torneira convencional foi obtido considerando-se o quociente entre a massa de uma torneira e a massa total de torneiras transportadas em caminhão pesado. A energia embutida nesses processos, calculada de acordo com a Equação 5, é de 14,54 MJ.

A Tabela 6 apresenta o consumo de energia considerado para possibilitar a etapa de uso da torneira. Esse modelo de torneira não apresenta consumo de energia operacional (considerada a energia para acionamento dela). $\mathrm{O}$ ponto de consumo também não é conectado a nenhum sistema de aquecimento de água, não havendo consumo energético para esse fim. $\mathrm{O}$ consumo de água nos quatro anos de vida útil é utilizado para o cálculo da energia necessária ao bombeamento desse volume de água ao reservatório superior (considerando a potência da motobomba igual a 0,25 CV). O consumo de água, em metros cúbicos, nos 4 anos de vida útil é calculado como o quociente entre o volume total de água consumido nos lavatórios do bloco de salas e o número total 
de torneiras de lavatório, ou seja, 14. O cálculo do consumo de água em cada torneira nos 4 anos de vida útil foi realizado por meio da multiplicação do índice de consumo médio apresentado na Tabela 1 pelo número de usuários e pelo número de dias letivos em 4 anos. Em seguida, o consumo total nos lavatórios do edifício foi dividido entre as 14 torneiras existentes, resultando em um consumo de $31,57 \mathrm{~m}^{3}$ de água por torneira. São considerados os dispêndios energéticos resultantes do tratamento desse volume de água e do posterior tratamento de efluentes. Para as necessidades de manutenção é considerada apenas a limpeza dos arejadores pela própria equipe de manutenção do campus, o que não foi considerado como consumo energético significativo para este estudo. O consumo energético na fase de uso, calculado de acordo com a Equação 6, é de 97,96 MJ.

Tabela 4 - Consumo de energia para extração, beneficiamento e transporte das matérias-primas que compõem a torneira convencional

\begin{tabular}{|c|c|c|c|c|c|c|}
\hline Matéria-prima & $\begin{array}{c}\text { Massa da } \\
\text { matéria- } \\
\text { prima (kg) } \\
\mathrm{M}_{\mathrm{mp}}\end{array}$ & $\begin{array}{c}\text { Consumo } \\
\text { energético } \\
\text { na extração } \\
(\mathbf{M J} / \mathbf{k g}) \\
\mathrm{CE}_{\mathrm{ext}}\end{array}$ & $\begin{array}{c}\text { Distância } \\
\text { (km) } \\
\mathrm{D}_{\mathrm{mp}}\end{array}$ & $\begin{array}{c}\% \text { da } \\
\text { carga no } \\
\text { transporte } \\
\text { PC }\end{array}$ & $\begin{array}{c}\text { Consumo } \\
\text { energético } \\
\text { no } \\
\text { transporte } \\
\text { (MJ/km) } \\
\mathrm{CE}_{\mathrm{tmp}}\end{array}$ & 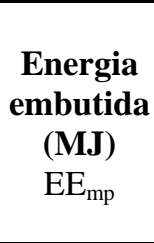 \\
\hline Cobre (transf. latão) & 0,3748 & 38,60 & 2440 & 0,0042 & 11,67 & 15,65 \\
\hline Zinco (transf. latão) & 0,2397 & 73,20 & 1361 & 0,0027 & 11,67 & 17,97 \\
\hline Cerâmica & 0,0034 & 3,73 & 349 & $3,8 \times 10^{-5}$ & 11,67 & 0,01 \\
\hline Polioximetileno & 0,0815 & 1,44 & 575 & 0,0016 & 11,67 & 0,23 \\
\hline Borracha & 0,0015 & 143,00 & 896 & 0,0002 & 11,67 & 0,23 \\
\hline Papel/papelão & 0,0082 & 17,51 & 112 & 0,0008 & 11,67 & 0,15 \\
\hline \multicolumn{6}{|c|}{ Energia embutida na extração e processamento de matérias-primas (MJ) } & 34,24 \\
\hline
\end{tabular}

Tabela 5 - Energia embutida na produção da torneira convencional

\begin{tabular}{|c|c|c|c|c|c|}
\hline 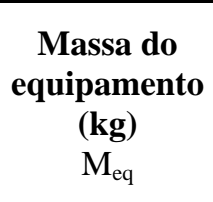 & $\begin{array}{c}\text { Consumo } \\
\text { energético na } \\
\text { fábrica } \\
(\mathbf{M J} / \mathbf{k g}) \\
\mathrm{CE}_{\mathrm{pr}}\end{array}$ & $\begin{array}{c}\text { Distância } \\
\text { (km) } \\
\mathrm{D}_{\mathrm{pr}}\end{array}$ & $\begin{array}{c}\text { \% da } \\
\text { carga no } \\
\text { transporte } \\
\text { PC }\end{array}$ & $\begin{array}{c}\text { Consumo } \\
\text { energético no } \\
\text { transporte } \\
(\mathbf{M J} / \mathbf{k m}) \\
\mathrm{CE}_{\mathrm{tpr}}\end{array}$ & $\begin{array}{c}\text { Energia } \\
\text { embutida na } \\
\text { fabricação (MJ) } \\
E_{\mathrm{pr}}\end{array}$ \\
\hline 0,7091 & 19,48 & 22 & 0,284 & 11,67 & 14,54 \\
\hline
\end{tabular}

Tabela 6 - Consumo de energia na utilização da torneira convencional

\begin{tabular}{|c|c|c|c|c|c|c|c|c|}
\hline \multirow[b]{2}{*}{$\begin{array}{c}\text { Índice de } \\
\text { consumo } \\
\text { (l/usuário } \\
\text { /dia) }\end{array}$} & \multirow[b]{2}{*}{$\begin{array}{c}\text { № de } \\
\text { usuários }\end{array}$} & \multirow[b]{2}{*}{$\begin{array}{l}\text { Dias } \\
\text { letivos } \\
(4 \\
\text { anos })\end{array}$} & \multirow[b]{2}{*}{$\begin{array}{l}\text { № de } \\
\text { torneiras }\end{array}$} & \multirow[b]{2}{*}{$\begin{array}{c}\text { Consumo } \\
\text { de água } \\
\text { nos } 4 \\
\text { anos }\left(\mathbf{m}^{3}\right) \\
\mathrm{CA}_{\mathrm{eq}} \mathrm{xVU}\end{array}$} & \multicolumn{4}{|c|}{ Consumo energético } \\
\hline & & & & & $\begin{array}{c}\text { Bombeamento } \\
\left(\mathbf{M J} / \mathbf{m}^{3}\right) \\
\mathrm{CE}_{\mathrm{bo}}\end{array}$ & $\begin{array}{c}\text { Tratamento } \\
\text { e } \\
\text { distribuição } \\
\text { da água } \\
\left(\mathbf{M J} / \mathbf{m}^{3}\right) \\
\mathrm{CE}_{\mathrm{ab}}\end{array}$ & $\begin{array}{c}\text { Coleta e } \\
\text { tratamento } \\
\text { do esgoto } \\
\left(\mathbf{M J} / \mathbf{m}^{3}\right) \\
\mathrm{CE}_{\mathrm{esg}}\end{array}$ & $\begin{array}{c}\text { Total } \\
\text { na } \\
\text { etapa } \\
\text { de } \\
\text { uso } \\
\text { (MJ) } \\
\mathrm{CE}_{\mathrm{u}}\end{array}$ \\
\hline 0,538 & 921 & 892 & 14 & 31,57 & 0,547 & 1,908 & 0,648 & 97,96 \\
\hline
\end{tabular}


A Tabela 7 apresenta o consumo de energia para simples deposição da torneira em aterro ao final da vida útil. Nesse caso, é apenas considerado o consumo energético referente ao transporte da torneira ao local apontado pelos órgãos ambientais do município. Para calcular a percentagem representativa da massa do equipamento em comparação à carga total transportada no meio de transporte, foi considerado que o caminhão transporta, ao final da vida útil, as 14 torneiras instaladas no edifício. O consumo energético para disposição final de uma torneira convencional, calculado de acordo com a Equação 7, é igual a 4,92 MJ.

\section{Consumo de energia no ciclo de vida: torneira economizadora de água}

As mesmas considerações feitas no cálculo do consumo energético no ciclo de vida da torneira convencional foram realizadas nos cálculos que envolvem as diferentes fases do ciclo de vida da torneira economizadora de água. As Tabelas 8 a 11 apresentam os valores obtidos nas fases de produção, uso e disposição final da torneira economizadora de água. A energia embutida para extração, beneficiamento e transporte das matériasprimas até a indústria, calculada de acordo com a Equação 3, é de 35,01 MJ para a torneira economizadora de água.

A energia embutida nos processos de manufatura (na indústria de metais sanitários) e transporte da torneira economizadora, considerando-se a percentagem representativa da massa de uma torneira com relação ao total transportado em caminhão pesado, calculada de acordo com a Equação 5, é de 15,54 MJ (Tabela 9).

A principal diferença no consumo energético calculado no presente estudo de caso encontra-se na fase de uso das torneiras. O consumo energético decorrente da utilização da torneira economizadora de água foi calculado de acordo com os mesmos critérios mencionados para a torneira convencional. A torneira economizadora de água utilizada neste estudo de caso também não apresenta consumo de energia operacional, e o ponto de consumo não é conectado a sistemas de aquecimento de água, assim como no caso da torneira convencional. O consumo de água em cada torneira economizadora durante a vida útil foi calculado com base no índice de consumo médio para o modelo de torneira apresentado na Tabela 1. Esse valor foi multiplicado pelo número de usuários e pelo número de dias letivos em 4 anos. O valor obtido (consumo total nos lavatórios do edifício) foi dividido entre as 14 torneiras economizadoras instaladas no período, resultando em um consumo de $23,24 \mathrm{~m}^{3}$ de água por torneira. Com relação à necessidade de manutenção, neste caso também foi considerada a simples limpeza de arejadores, o que não foi considerado como um dispêndio energético significativo para este estudo. O consumo de energia na fase de uso da torneira economizadora foi estimado em 72,11 MJ (Tabela 10), de acordo com a Equação 6.

$\mathrm{Na}$ fase de disposição final da torneira economizadora, o consumo energético considerado para deposição das 14 torneiras em aterro ao final da vida útil, calculado de acordo com a Equação 7, é de 4,92 MJ (Tabela 11). No cálculo da percentagem representativa da massa do equipamento em comparação à carga total transportada no meio de transporte, foi considerado que o caminhão transporta, ao final da vida útil, as 14 torneiras economizadoras de água instaladas no edifício.

Tabela 7 - Consumo de energia para disposição final da torneira convencional

\begin{tabular}{c|c|c|c}
\hline $\begin{array}{c}\text { Distância } \\
(\mathbf{k m}) \\
\mathrm{D}_{\mathrm{di}}\end{array}$ & $\begin{array}{c}\text { Consumo energético no } \\
\text { transporte }(\mathbf{M J} / \mathbf{k m}) \\
\mathrm{CE} E_{\mathrm{tdi}}\end{array}$ & $\begin{array}{c}\text { \% da carga no } \\
\text { transporte } \\
\mathrm{PC}\end{array}$ & $\begin{array}{c}\text { Consumo energético na } \\
\text { disposição final (MJ) } \\
\mathrm{CE}_{\mathrm{di}}\end{array}$ \\
\hline 5,9 & 11,67 & 7,14 & $\mathbf{4 , 9 2}$ \\
\hline
\end{tabular}


Tabela 8 - Consumo de energia para extração, beneficiamento e transporte das matérias-primas que compõem a torneira economizadora de água

\begin{tabular}{|c|c|c|c|c|c|c|}
\hline Matéria-prima & $\begin{array}{c}\text { Massa da } \\
\text { matéria- } \\
\text { prima }(\mathrm{kg}) \\
\mathrm{M}_{\mathrm{mp}}\end{array}$ & $\begin{array}{c}\text { Consumo } \\
\text { energético } \\
\text { na } \\
\text { extração } \\
\text { (MJ/kg) } \\
\mathrm{CE}_{\text {ext }} \\
\end{array}$ & $\begin{array}{c}\text { Distância } \\
\text { (km) } \\
\text { D }_{\mathbf{m p}}\end{array}$ & $\begin{array}{c}\text { \% da } \\
\text { carga no } \\
\text { transporte } \\
\text { Pc }\end{array}$ & $\begin{array}{c}\text { Consumo } \\
\text { energético } \\
\text { no } \\
\text { transporte } \\
\text { (MJ/km) } \\
\text { CE } \text { tmp }_{\text {mo }} \\
\end{array}$ & $\begin{array}{c}\text { Energia } \\
\text { embutida } \\
\text { (MJ) } \\
\text { EE }_{\text {mp }}\end{array}$ \\
\hline $\begin{array}{l}\text { Cobre (transf. } \\
\text { latão) }\end{array}$ & 0,3608 & 38,60 & 2440 & 0,0040 & 11,67 & 15,07 \\
\hline $\begin{array}{l}\text { Zinco (transf. } \\
\text { latão) }\end{array}$ & 0,2306 & 73,20 & 1361 & 0,0026 & 11,67 & 17,29 \\
\hline Aço inoxidável & 0,0141 & 23,03 & 1314 & 0,0002 & 11,67 & 0,35 \\
\hline Polioximetileno & 0,0607 & 1,44 & 575 & 0,0012 & 11,67 & 0,17 \\
\hline Borracha & 0,0031 & 143,00 & 896 & 0,0003 & 11,67 & 0,47 \\
\hline Papel/papelão & 0,0885 & 17,51 & 112 & 0,0089 & 11,67 & 1,66 \\
\hline \multicolumn{6}{|c|}{ Energia embutida na extração e processamento de matérias-primas (MJ) } & 35,01 \\
\hline
\end{tabular}

Tabela 9 - Energia embutida na produção da torneira economizadora de água

\begin{tabular}{|c|c|c|c|c|c|}
\hline $\begin{array}{c}\text { Massa do } \\
\text { equipamento } \\
\text { (kg) } \\
\mathbf{M}_{\text {eq }}\end{array}$ & $\begin{array}{c}\text { Consumo } \\
\text { energético } \\
\text { na fábrica } \\
(\mathrm{MJ} / \mathrm{kg}) \\
\mathrm{CE}_{\mathrm{pr}}\end{array}$ & $\begin{array}{c}\text { Distância } \\
\text { (km) } \\
\mathbf{D}_{\mathbf{p r}}\end{array}$ & $\begin{array}{c}\text { \% da } \\
\text { carga no } \\
\text { transporte } \\
\text { Pc }\end{array}$ & $\begin{array}{c}\text { Consumo } \\
\text { energético no } \\
\text { transporte } \\
(\mathrm{MJ} / \mathbf{k m}) \\
\mathrm{CE}_{\mathrm{tpr}}\end{array}$ & $\begin{array}{c}\text { Energia } \\
\text { embutida na } \\
\text { fabricação } \\
(\mathrm{MJ}) \\
\text { EE }_{\mathrm{pr}}\end{array}$ \\
\hline 0,7578 & 19,48 & 22 & 0,303 & 11,67 & 15,54 \\
\hline
\end{tabular}

Tabela 10 - Consumo de energia na utilização da torneira economizadora de água

\begin{tabular}{|c|c|c|c|c|c|c|c|c|}
\hline \multirow{2}{*}{$\begin{array}{c}\text { Índice de } \\
\text { consumo } \\
\text { (l/usuário/dia) }\end{array}$} & \multirow{2}{*}{$\begin{array}{c}\text { No de } \\
\text { usuários }\end{array}$} & \multirow{2}{*}{$\begin{array}{c}\text { Dias } \\
\text { letivos } \\
(4 \\
\text { anos })\end{array}$} & \multirow{2}{*}{$\begin{array}{c}\text { No de } \\
\text { torneiras }\end{array}$} & \multirow[b]{2}{*}{$\begin{array}{c}\text { Consumo } \\
\text { de água } \\
\text { nos } 4 \\
\text { anos }\left(\mathrm{m}^{3}\right) \\
\mathrm{CA}_{\mathrm{eq}} \times \mathrm{VU}\end{array}$} & \multicolumn{4}{|c|}{ Consumo energético } \\
\hline & & & & & $\begin{array}{l}\text { Bombeamento } \\
\left(\mathrm{MJ} / \mathrm{m}^{3}\right) C E_{\mathrm{bo}}\end{array}$ & $\begin{array}{c}\text { Tratamento } \\
\text { e } \\
\text { distribuição } \\
\text { da água } \\
\left({\left.\mathrm{MJ} / \mathbf{m}^{3}\right)}^{3}\right. \\
\mathrm{CE}_{\mathrm{ab}}\end{array}$ & $\begin{array}{c}\text { Coleta e } \\
\text { tratamento } \\
\text { do esgoto } \\
\left(\mathrm{MJ} / \mathbf{m}^{3}\right) \\
\mathrm{CE}_{\text {esg }}\end{array}$ & $\begin{array}{c}\text { Total } \\
\text { na } \\
\text { etapa } \\
\text { de } \\
\text { uso } \\
\text { (MJ) } \\
\text { CE }_{\mathbf{u}}\end{array}$ \\
\hline 0,396 & 921 & 892 & 14 & 23,24 & 0,547 & 1,908 & 0,648 & 72,11 \\
\hline
\end{tabular}

Tabela 11 - Consumo de energia para disposição final da torneira economizadora de água

\begin{tabular}{c|c|c|c}
\hline $\begin{array}{c}\text { Distância (km) } \\
\mathbf{D}_{\mathbf{d i}}\end{array}$ & $\begin{array}{c}\text { Consumo energético no } \\
\text { transporte }(\mathbf{M J} / \mathbf{k m}) \mathbf{C E}\end{array}$ & $\begin{array}{c}\text { \% da carga no } \\
\text { transporte Pc }\end{array}$ & $\begin{array}{c}\text { Consumo energético na } \\
\text { disposição final (MJ) }\end{array}$ \\
\hline 5,9 & 11,67 & 7,14 & 4,92 \\
\hline
\end{tabular}

\section{Comparação entre os consumos de energia no ciclo de vida}

A Figura 3 apresenta a energia embutida na extração de matérias-primas para os dois modelos de torneira analisados. Os metais cobre e zinco, que têm a maior contribuição em massa na composição da torneira, também possuem a maior contribuição na energia embutida na etapa de extração e processamento das matérias-primas.
A Figura 4 apresenta o consumo energético nas diversas etapas consideradas no ciclo de vida das torneiras. É possível identificar os subitens envolvidos na etapa de uso (bombeamento, tratamento de água e de esgoto) das torneiras como preponderantes na diferenciação do consumo energético total. 


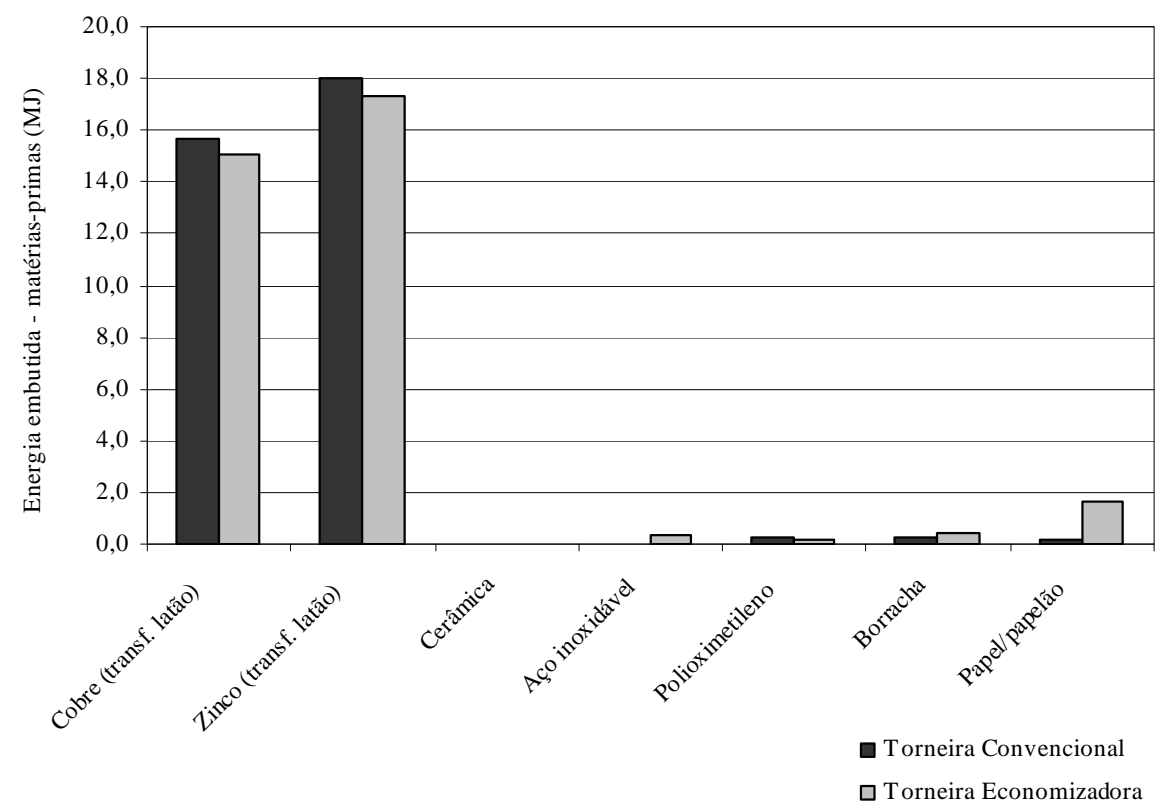

Figura 3 - Energia embutida na extração e processamento de matérias-primas para os dois modelos de torneira analisados

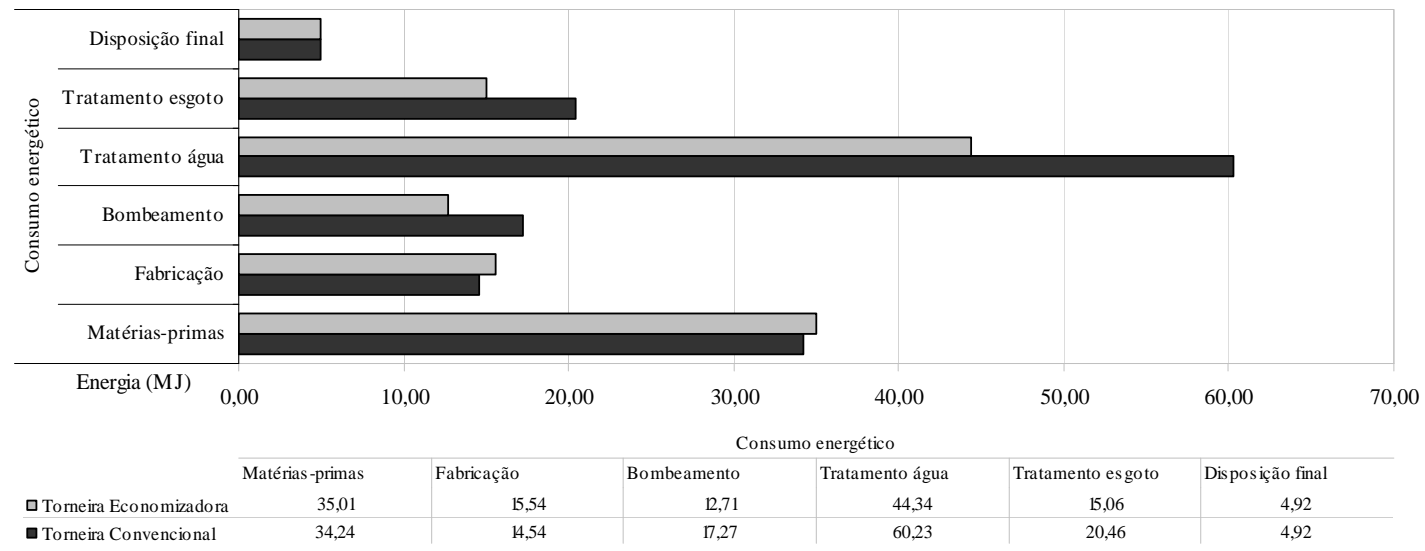

Figura 4 - Consumo energético nas etapas consideradas no ciclo de vida da torneira convencional e da torneira economizadora de água

A Figura 5 apresenta o consumo energético total no ciclo de vida das torneiras analisadas. O consumo energético total da torneira convencional é de 151,66 MJ, sendo aproximadamente 64,6\% desse valor referente à etapa de uso. O consumo energético total da torneira economizadora de água é de 127,58 MJ. Para o modelo economizador de água, aproximadamente $56,5 \%$ do total energético despendido no ciclo de vida é referente à etapa de uso.

No estudo de caso, a etapa de uso das torneiras é a etapa que apresentou maior consumo energético: $64,6 \%$ e $56,5 \%$ do consumo energético total para as torneiras convencional e economizadora de água respectivamente. A segunda etapa com maior contribuição foi a etapa de produção. Nesse caso, com 32,2\% do consumo energético total para a torneira convencional e 39,6\% para a torneira economizadora de água. Como na etapa de disposição final foi considerado apenas o simples descarte em aterro, o consumo energético considerado é relativo à necessidade de transporte do equipamento ao final da vida útil e equivale a $3,2 \%$ do consumo energético total para a torneira convencional e a $3,9 \%$ para a torneira economizadora de água. A etapa de uso é a etapa com maior contribuição no cálculo do consumo energético total dos dois modelos analisados no estudo de caso. Como a etapa de uso leva em consideração o consumo de água e o consumo energético decorrente dessa utilização da água, o modelo economizador apresenta um consumo energético menor no ciclo de vida. 


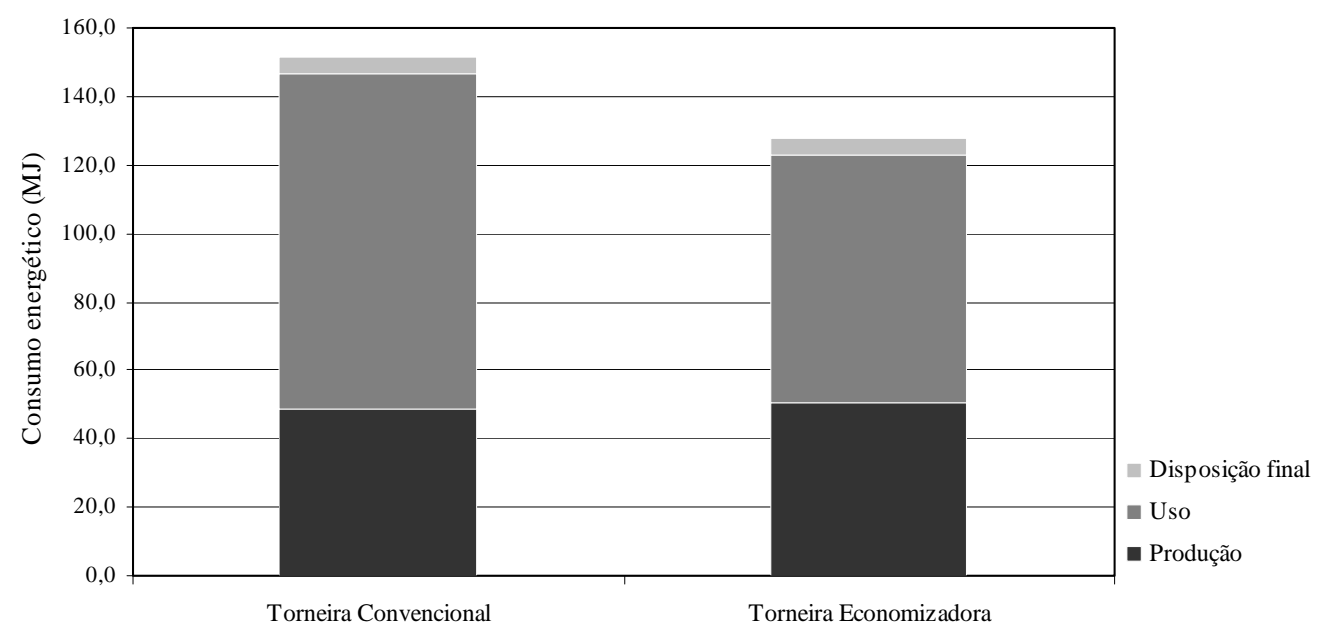

Figura 5 - Consumo energético total no ciclo de vida dos dois modelos de torneiras

\section{Conclusões}

Ao proceder à escolha entre dois ou mais produtos ou sistemas, algumas questões necessitam ser respondidas. Existem diversas variáveis relacionadas a esse tipo de escolha: consumo de recursos e outros impactos ambientais envolvidos, além de variáveis econômicas, sociais e culturais. Um exemplo de critério comumente utilizado para a decisão é o preço inicial. Nesse caso, o modelo economizador de água utilizado no estudo de caso seria preterido, uma vez que apresenta valor de compra aproximadamente quatro vezes superior ao da torneira convencional considerada no estudo.

O presente artigo buscou apresentar um método para escolha entre equipamentos hidrossanitários por meio da quantificação do gasto energético no ciclo de vida desses equipamentos. O método levou em consideração o consumo de água na vida útil dos equipamentos hidrossanitários e como esse consumo de água acarretou em diferenças no consumo de energia na fase de uso.

O método para avaliação do consumo de energia no ciclo de vida de equipamentos hidrossanitários mostrou-se válido quando de sua utilização em um estudo de caso. O consumo energético total da torneira convencional calculado foi de 151,66 MJ. A etapa de uso apresentou uma parcela de contribuição de aproximadamente $64,6 \%$ desse valor e incluiu a energia decorrente do consumo de água no ciclo de vida (para bombeamento e tratamento da água e posterior tratamento dos efluentes). O consumo energético total calculado para a torneira economizadora de água foi de 127,58 MJ, com aproximadamente 56,5\% desse valor referente à etapa de uso. O modelo de torneira economizadora de água apresentou consumo energético menor no ciclo de vida. Com base no método proposto, por proporcionar economia de água e de energia no ciclo de vida, a torneira economizadora de água mostrou-se a escolha viável quando comparada à torneira convencional.

\section{Referências}

ABEYSUNDARA, U. G. Y.; BABEL, S.; GHEEWALA, S. A Matrix in Life Cycle Perspective for Selecting Sustainable Materials for Buildings in Sri Lanka. Building and

Environment, v. 44, n. 5, p. 997-1004, 2009.

ARENA, A. P.; ROSA, D. de. Life Cycle Assessment of Energy and Environmental Implications of the Implementation of Conservation Technologies in School Buildings in Mendoza, Argentina. Building and Environment, v. 38, n. 2, p. 359-368, 2003.

ASSOCIAÇÃO BRASILEIRA DE CELULOSE E PAPEL. Relatório Anual 2009/2010: estatísticas Bracelpa. São Paulo: BRACELPA, 2010.

ASSOCIAÇÃO BRASILEIRA DE NORMAS TÉCNICAS. NBR 5626: instalação predial de água fria. Rio de Janeiro, 1998.

\section{ASSOCIAÇÃO BRASILEIRA DE NORMAS} TÉCNICAS. NBR ISO 14040: gestão ambiental: avaliação do ciclo de vida: princípios e estrutura. Rio de Janeiro, 2009a.

\section{ASSOCIAÇÃO BRASILEIRA DE NORMAS}

TÉCNICAS. NBR ISO 14044: gestão ambiental: avaliação do ciclo de vida: requisitos e orientações. Rio de Janeiro, 2009b.

\section{ASSOCIAÇÃO BRASILEIRA DE NORMAS} TÉCNICAS. NBR 15575-1: edifícios habitacionais de até cinco pavimentos: desempenho: parte 1: requisitos gerais. Rio de Janeiro, 2010. 
BLANCHARD, S.; REPPE, P. Life Cycle Analysis of a Residential Home in Michigan. Center for Sustainable Systems, Report No. CSS98-05. Ann Arbor: University of Michigan, 1998.

BRASIL. Diagnóstico dos Serviços de Água e Esgotos. Brasília, DF: Sistema Nacional de Informações sobre Saneamento, 2007.

BRIBIÁN, I. Z.; USÓN, A. A.; SCARPELLINI, S. Life Cycle Assessment in Buildings: state-of-theart and simplified LCA methodology as a complement for building certification. Building and Environment, v. 44, n. 12, p. 2510-2520, 2009.

CYBIS, L. F.; SANTOS, C. V. J. dos. Análise do Ciclo de Vida (ACV) Aplicada à Indústria da Construção Civil: estudo de caso. In: CONGRESSO INTERAMERICANO DE ENGENHARIA SANITÁRIA E AMBIENTAL, 27., Porto Alegre, 2000. Anais... Porto Alegre, 2000.

HIRATA, A. Y. Programa Eficiência Energética nas Estações de Tratamento de Esgoto (ETE) Parque Novo Mundo e ABC. Disponível em: <www.agendasustentavel.com.br>. Acesso em: 25 jun. 2009.

HUBERMAN, N., PEARLMUTTER, D. A LifeCycle Energy analysis of Building Materials in the Negev Desert. Energy and Buildings, v. 40, n. 5, p 837-848, 2007.

MINISTÉRIO DE MINAS E ENERGIA. Sinopse 2009: mineração e transformação mineral (metálicos e não metálicos). Brasília, DF, 2009.

MINISTÉRIO DE MINAS E ENERGIA. Balanço Energético Nacional: ano-base 2009. Brasília, 2010.

NORGATE, T. E.; JAHANSHAHI, S.; RANKIN, W. J. Assessing the Environmental Impact of Metal Production Processes. Journal of Cleaner Production, v. 15, n. 8-9, p. 838-848, 2007.

PERTEL, M. et al. Avaliação da Sazonalidade do Consumo de Água e Energia em Uma Edificação Residencial de Alto Padrão. In: CONGRESSO INTERAMERICANO DE ENGENHARIA SANITÁRIA E AMBIENTAL, 31., Santiago, 2008. Proceedings... Santiago, 2008.

RIBEIRO, F. de M. Inventário de Ciclo de Vida da Geração Hidrelétrica no Brasil: Usina de Itaipu: primeira aproximação. São Paulo, 2003. Dissertação (Mestrado em Engenharia Civil) Escola Politécnica, Universidade de São Paulo, São Paulo, 2003.
SCHEUER, C.; KEOLEAIN, G. A.; REPPE, P. Life Cycle Energy and Environmental Performance of a New University Building: modeling challenges and design implications. Energy and Buildings, v. 35, n. 10, p. 1049-1064, 2003.

SEPPÄLÄ, J. et al. The Finnish Metals Industry and the Environment. Resources, Conservation and Recycling, v. 35, n. 1-2, p. 61-76, 2002.

SILVA, V. G. Avaliação da Sustentabilidade de Edifícios de Escritórios Brasileiros: diretrizes e base metodológica. São Paulo, 2003. Tese (Doutorado em Engenharia) - Escola Politécnica, Universidade de São Paulo, São Paulo, 2003.

SILVEIRA, S.; REIS, L. B. dos; GALVÃO, L. C. R. A Energia Elétrica no Âmbito do Desenvolvimento Sustentável. In: REIS, L. B. dos; SILVEIRA, S. (Org.). Energia Elétrica Para o Desenvolvimento Sustentável: uma visão multidisciplinar. São Paulo: Edusp, 2000.

SOARES, S. R., PEREIRA, S. W. Inventário da Produção de Pisos e Tijolos Cerâmicos no Contexto da Análise do Ciclo de Vida. Ambiente Construído, Porto Alegre, v. 4, n. 2, p. 83-94, abr./jun. 2004.

SOARES, S. R., SOUZA, D. M. de, PEREIRA, S. W. A avaliação do Ciclo de Vida no Contexto da Construção Civil. In: SATTLER, M. A.; PEREIRA, F. A. R. Construção e Meio Ambiente. Porto Alegre: Habitare, 2006. v. 7.

SPEZZIA JUNIOR, L. C. Estimativa de Consumo: Schneider Motobombas. Mensagem pessoal recebida por <andreza@joinville.udesc.br>, em 08 jul. 2009.

TABORIANSKI, V. M.; SIMONI, R. A.; PRADO, R. T. A. Elaboração de Inventário de Consumo de Energia no Ciclo de Vida dos Materiais Utilizados em Fachadas de Edifícios no Brasil. In: Encontro Nacional de Tecnologia do Ambiente Construído, 12., Fortaleza, 2008. Anais... Fortaleza: ANTAC, 2008.

TAVARES, S. F. Metodologia de Análise do Ciclo de Vida Energético de Edificações Residenciais Brasileiras. Florianópolis, 2006. Tese (Doutorado em Engenharia Civil) - Programa de Pós-Graduação em Engenharia Civil, Universidade Federal de Santa Catarina, Florianóplois, 2006. 
TAVARES, S. F.; LAMBERTS, R. Estudos Comparativos Sobre Consumo Energético no Ciclo de Vida de Edificações Residenciais do Brasil, Austrália e Suécia. In: CONFERÊNCIA LATINOAMERICANA DE CONSTRUÇÃO SUSTENTÁVEL; ENCONTRO NACIONAL DE TECNOLOGIA NO AMBIENTE CONSTRUÍDO, 10., São Paulo, 2004. Anais... São Paulo: ANTAC, 2004.

TSUTIYA, M. T. Redução do Custo de Energia Elétrica em Estações Elevatórias de Água e Esgoto. In: CONGRESSO BRASILEIRO DE ENGENHARIA SANITÁRIA E AMBIENTAL, 19., Foz do Iguaçu, 1997. Anais... Foz do Iguaçu, 1997.

\section{UNITED NATIONS ENVIRONMENT}

PROGRAMME. Life Cycle Assessment: what it is and how to do it. França: UNEP, 1996.
UNITED STATES ENVIRONMENTAL PROTECTION AGENCY. Report on the International Workshop on Electricity Data for Life Cycle Inventories. EPA 600-R-02-041. Cincinnati: EPA, 2002.

VEIGA, F. da. Consumo de Água no Parque Fabril da Docol. Mensagem pessoal recebida por <andreza@olimpiatur.com.br>, em 23 jul. 2011.

VERBEECK, G.; HENS, H. Life Cycle Inventory of Buildings: a contribution analysis. Building and Environment, v. 45, n. 4, p. 964-967, 2010.

\section{Agradecimentos}

Os autores agradecem à Companhia Águas de Joinville, pelo empréstimo dos hidrômetros utilizados no estudo de caso; à empresa Docol Metais Sanitários e às fontes confidenciais, pela disponibilização de dados de produção; e à equipe da prefeitura do campus do Centro de Ciências Tecnológicas da UDESC.

Revista Ambiente Construído

Associação Nacional de Tecnologia do Ambiente Construído

Av. Osvaldo Aranha, 99 - 3o andar, Centro

Porto Alegre - RS - Brasil

CEP $90035-190$

Telefone: +55 (51) 3308-4084

Fax: +55 (51) 3308-4054

www. seer. ufrgs. br/ ambienteconstruido

E-mail: ambienteconstruido@ufrgs.br 